\title{
Desempenho de bezerros em pastagem de capim-marandu recebendo suplementação com concentrados balanceados para diferentes níveis de produção
}

\author{
Rodolfo Marques de Brito ${ }^{1}$, Alexandre Amstalden Moraes Sampaio ${ }^{2}$, Alexandre Rodrigo \\ Mendes Fernandes ${ }^{3}$, Kleber Tomás de Resende ${ }^{4}$, Wignez Henrique ${ }^{5}$, Rymer Ramiz Tullio ${ }^{6}$
}

${ }^{1}$ Unirp, São José do Rio Preto, SP.

2 Departamento de Zootecnia/FCAV/UNESP, Jaboticabal, SP. Bolsista CNPq

${ }^{3}$ Doutorando pela FCAV/UNESP, Jaboticabal, SP.

${ }^{4}$ Departamento de Zootecnia/FCAV/UNESP, Jaboticabal, SP.

5 UPD/Apta/SAA, São José do Rio Preto, SP.

${ }^{6}$ CPPSE/Embrapa, São Carlos, SP.

RESUMO - Avaliou-se o fornecimento de concentrado para bezerros mantidos em pastagens de Brachiaria brizantha cv. Marandu durante a época seca do ano. Utilizaram-se 16 machos não-castrados da raça Canchim, com 7 meses de idade e $250 \mathrm{~kg}$, distribuídos em delineamento inteiramente ao acaso em esquema fatorial $2 \times 2$, no qual os fatores foram suplementos balanceados para dois potenciais de fermentação microbiana - 9,5 e $11,0 \mathrm{~g}$ de proteína bruta microbiana/MJ energia metabolizável fermentável e para ganhos de peso corporal (GPC) de 0,5 e $1,0 \mathrm{~kg} / \mathrm{dia}$. Os animais receberam suplementação individual diária por 168 dias, após 21 dias de adaptação. A ingestão diária de forragem foi estimada em 5,91 kg matéria seca/ animal. A suplementação para ganho de peso corporal de $0,5 \mathrm{~kg} / \mathrm{dia}$ proporcionou ganhos de peso e conversão alimentar de $0,94 \mathrm{~kg} / \mathrm{dia}$ e $2,08 \mathrm{~kg}$ suplemento $/ \mathrm{kg}$ ganho, respectivamente, resultados inferiores aos obtidos para ganho de peso corporal de $1 \mathrm{~kg} /$ dia $(1,09 \mathrm{~kg} /$ dia e $3,18 \mathrm{~kg}$ suplemento/kg ganho, respectivamente). Não houve efeito do potencial de fermentação sobre o ganho de peso corporal, a conversão alimentar e a área de olho-de-lombo, no entanto, a espessura final de gordura de cobertura foi maior com o potencial de fermentação mais elevado. A suplementação para ganho de peso corporal de $0,5 \mathrm{~kg} /$ dia mostrou melhor resultado econômico, mas não permitiu obter peso apropriado para abate. A suplementação com concentrado formulado para aumentar a eficiência de síntese de proteína microbiana no rúmen, porém reduziu a rentabilidade do sistema.

Palavras-chave: avaliação econômica, Brachiaria brizantha cv. Marandu, Canchim, ganho de peso, potencial de fermentação microbiana

\section{Performance of young bulls receiving supplementation with concentrate balanced for different levels of production on Brachiaria brizantha cv. Marandu pastures}

\footnotetext{
ABSTRACT - The supplementation of concentrate to young bulls kept in pastures of Brachiaria brizantha cv. Marandu during the dry season of the year was evaluated. A total of 16 young bulls from Canchim breed, with 7 mo old and $250 \mathrm{~kg}$, was allotted to a completely randomized design in $2 \times 2$ factorial arrangement. The factors consisted of balanced supplements for two potential of microbial fermentation -9.5 and $11.0 \mathrm{~g}$ microbial crude protein/MJ fermentable metabolizable energy and for weight gain of 0.5 and $1.0 \mathrm{~kg} / \mathrm{day}$. The animals were daily individually supplemented by 168 days, after 21 days of adaptation. The daily intake of forage was estimated in $5.91 \mathrm{~kg}$ dry matter/animal. The supplementation for $0.5 \mathrm{~kg} / \mathrm{day}$ of weight gain provided gains and feed conversion of $0.94 \mathrm{~kg} / \mathrm{day}$ and $2.08 \mathrm{~kg}$ supplement $/ \mathrm{kg}$ of gain, respectively, lower than the results obtained to weight gain of $1.0 \mathrm{~kg} / \mathrm{day}(1.09 \mathrm{~kg} / \mathrm{day}$ and $3.18 \mathrm{~kg}$ supplement $/ \mathrm{kg}$ gain, respectively). There was no effect of the fermentation potential on weight gain, feed conversion and ribeye area, but the final backfat thickness increased with the higher potential fermentation. The supplementation for $0.5 \mathrm{~kg}$ /day weight gain showed better economic outcome, but did not allow to obtain appropriate slaughter weight. The supplementation with concentrate formulated to increase the efficiency of rumen microbial protein synthesis, however, reduced the profitability of the system.
}

Key Words: body weight gain, Brachiaria brizantha cv. Marandu, Canchim, economic evaluation, fermentation potential

Este artigo foi recebido em 1/3/2007 e aprovado em 26/3/2008.

Correspondências devem ser enviadaspara sampaio@fcav.unesp.br. 


\section{Introdução}

No processo de desenvolvimento da pecuária de corte brasileira, os sistemas tradicionais de produção estão se transformando em sistemas empresariais com o objetivo de aumentar a produtividade e a rentabilidade do setor (Santos et al., 2002). Para isso, os trabalhos de pesquisa têm se concentrado em reduzir a idade ao primeiro acasalamento das novilhas (Rocha \& Lobato, 2002) e a idade ao abate dos machos (Restle et al., 2002). Reduzindo a idade de abate para 12 a 15 meses, aumenta-se o giro de capital e modifica-se o sistema de organização das propriedades, alterando a estrutura do rebanho (Sampaio et al., 1998).

Para que os animais sejam abatidos nessa idade, especialmente aqueles mantidos em pastagens, a taxa de crescimento corporal deve ser mantida sempre em níveis elevados. A redução do ganho e a perda de peso durante a estação seca do ano têm sido consideradas os fatores que mais comprometem o desenvolvimento dos bovinos no Centro-Oeste brasileiro (Lanna, 1996). A utilização de suplementos alimentares nesse tipo de sistema de produção tem se mostrado alternativa viável. A formulação desses suplementos depende, além de aspectos nutricionais, dos objetivos traçados para o sistema produtivo e da disponibilidade de forragem, uma vez que a produção de animais jovens para abate envolve ganhos de peso diário acima de $500 \mathrm{~g} /$ animal e consumo de suplemento que pode superar $1 \%$ do peso corporal (Paulino et al., 2002).

Neste trabalho, objetivou-se avaliar o desempenho bioeconômico de machos Canchim não-castrados durante a época seca do ano mantidos em pastagem de Brachiaria brizantha $\mathrm{cv}$. Marandu recebendo suplementos balanceados para dois níveis de ganho diário de peso corporal e dois potenciais de síntese microbiana.

\section{Material e Métodos}

O ensaio foi conduzido no Setor de Bovinocultura de Corte e no Laboratório de Ruminantes na Faculdade de Ciências Agrárias e Veterinárias - Unesp, Campus de Jaboticabal, São Paulo. A unidade está localizada na região norte do estado de São Paulo, nas coordenadas $21^{\circ} 15^{\prime} 22^{\prime \prime}$ de latitude Sul e 48 $18^{\prime} 58^{\prime \prime}$ de longitude Oeste. A altitude local é de 595 m e o clima, segundo classificação de Köppen, é do tipo subtropical com chuvas de verão e inverno relativamente seco. As médias anuais de precipitação pluviométrica, temperatura e umidade relativa do ar foram registradas em $1.400 \mathrm{~mm}, 21^{\circ} \mathrm{C} \mathrm{e} 70 \%$, respectivamente.

A área utilizada era formada com 9 ha de Brachiaria brizantha cv. Marandu, divididos em 24 piquetes, maneja- dos rotativamente. Durante o período das águas, foram aplicados $130 \mathrm{~kg} / \mathrm{ha}$ de nitrogênio parcelados em quatro aplicações. Após esse período, os piquetes foram mantidos sem animais por 30 dias, antes do início do experimento.

Utilizaram-se 16 bezerros não-castrados da raça Canchim, com 7 meses de idade e $250 \mathrm{~kg}$ de peso corporal, com alimentação suplementar em cocho privativo durante o aleitamento. $\mathrm{Na}$ desmama, os animais receberam tratamento contra endo e ectoparasitas e foram distribuídos em delineamento inteiramente casualizado e esquema fatorial $2 \times 2$, composto dos potenciais de fermentação e dos ganhos de peso. Os tratamentos consistiram dos suplementos balanceados para dois potenciais de fermentação microbiana (y): alto (11 g de proteína bruta microbiana/MJ de energia metabolizável fermentável) e baixo $(9,5 \mathrm{~g}$ de proteína bruta microbiana/MJ de energia metabolizável fermentável). Os suplementos foram balanceados e fornecidos em quantidades para promover ganho de peso corporal (GPC) de 0,5 e 1,0 kg/dia, ajustados conforme recomendações do AFRC (1993).

$\mathrm{O}$ experimento foi conduzido no período de junho a novembro de 2002 e teve duração de 168 dias, divididos em seis períodos, após 21 dias de adaptação.

Os animais foram mantidos nos piquetes em um único lote, das 6 às 18 h. Em seguida, diariamente, foram separados em baias individuais para receberem suplemento e permaneceram contidos por 12 horas durante o período noturno, das 18 às $6 \mathrm{~h}$ do dia seguinte, com água disponível. A prática de pastejo diurno foi adotada com base nos resultados descritos por Prates et al. (1995), Burgüer et al. (2000) e Bonfim et al. (2001). Os períodos de ocupação e descanso de cada piquete variaram de acordo com a estimativa de forragem disponível. Houve repetição do pastejo em parte dos piquetes e o período médio de ocupação foi de quatro dias. Antes da entrada dos animais em cada piquete, a forragem foi amostrada (Penati et al., 2005) na altura de corte de $5 \mathrm{~cm}$, pelo método do quadrado (McMeniman, 1997). O material foi analisado quanto aos teores de matéria seca (MS), proteína bruta (PB), matéria mineral (MM), extrato etéreo (EE), fibra em detergente neutro (FDN) e fibra em detergente ácido (FDA), conforme descrito por Silva (1990). Foram calculados o teor de matéria orgânica (MO), pela diferença entre os teores de MS e MM, e o teor de carboidratos totais (CT), conforme descrito por Sniffen et al. (1992), em que CT\% = $100-\mathrm{PB} \%-\mathrm{EE} \%-\mathrm{MM} \%$. A quantidade de MS da forragem disponível para cada $100 \mathrm{~kg}$ de peso corporal dos animais foi considerada oferta de forragem. O mesmo procedimento de amostragem foi adotado logo após a saída dos animais do piquete e a diferença entre a quantidade de forragem disponível antes e depois da 
entrada dos animais em cada piquete foi considerada estimativa do consumo de forragem pelos animais.

Após a saída dos animais das baias, as sobras de suplemento, quando existentes, foram retiradas, quantificadas e amostradas. As amostras foram agrupadas por período de 28 dias e acondicionadas em congelador a $-20^{\circ} \mathrm{C}$. Ao final de cada período, foram encaminhadas ao laboratório para análises químicas, segundo procedimentos descritos por Silva(1990).

Para formulação inicial dos suplementos, a ingestão de forragem foi estimada considerando $1,2 \mathrm{~kg}$ de FDN para cada $100 \mathrm{~kg}$ de peso corporal, conforme preconizado pelo NRC (1996).

A composição de cada um dos suplementos e as quantidades fornecidas foram reajustadas por período, ou seja, a cada 28 dias. Para esse balanceamento, foram considerados: a ingestão de suplemento no período anterior (a partir do controle de oferta e sobra de suplemento); a disponibilidade e a qualidade de forragem disponível no período anterior (a partir do controle da disponibilidade de forragem antes e depois da entrada dos animais em cada piquete); e o peso do animal; sempre mantendo os níveis de produção propostos para cada um dos níveis de suplemento (Tabela 1).

Uma vez que o pastejo foi feito em lote único, não foi realizada análise estatística desses resultados, portanto, as médias de composição e estimativa de ingestão da forragem são referentes a todos os níveis de suplemento avaliados.

Realizaram-se pesagens dos animais a cada 28 dias, após jejum de alimentos sólidos durante 15 horas, quando também foram monitorados por ultra-som o desenvolvimento muscular e a deposição de gordura. Para essa avaliação, o animal foi imobilizado em tronco individual e a área de avaliação foi limpa, tosquiada a $1 \mathrm{~mm}$ e recoberta por uma camada espessa de óleo de soja. Foram tomadas as medidas de área de olho-de-lombo (AOL) e da espessura de gordura de cobertura (EGC) do músculo Longissimus, sob a $12^{\text {a }}$ costela. Cada mensuração foi realizada em duplicata e sua média foi utilizada na análise final.

As análises de ingestão de suplementos e de nutrientes e das características de desempenho foram feitas utilizando-se delineamento inteiramente ao acaso, em esquema fatorial $2 \times 2$ (ganho de peso estimado $\times$ potencial de fermentação microbiana). Quando houve interação dos fatores, as médias foram comparadas pelo teste Tukey, a 5\% de probabilidade (Sampaio, 1998). A análise econômica dos níveis de suplementação foi realizada agregando-se as médias de desempenho e as quantidades de insumos utilizadas no período experimental. Adotou-se a metodologia de fluxo de caixa para avaliação do valor presente líquido
Tabela 1 - Composição dos suplementos e características das dietas fornecidas a bezerros Canchim não-castrados mantidos em pastagem de capim-marandu

\begin{tabular}{|c|c|c|c|c|}
\hline & \multicolumn{2}{|c|}{ Baixo $\mathrm{GPC}^{1}$} & \multicolumn{2}{|c|}{ Alto GPC } \\
\hline & Baixo $y^{2}$ & Alto y & Baixo y & Alto $y$ \\
\hline \multicolumn{5}{|c|}{ Composição do suplemento (\%) } \\
\hline Milho em grão moído & 47,4 & 33,3 & 50,8 & 27,8 \\
\hline Farelo de algodão & 20,7 & 20,7 & 13,1 & 13,1 \\
\hline Farelo de soja & 5,8 & 19,9 & 19,6 & 42,6 \\
\hline Soja em grão moída & 22,8 & 22,8 & 14,4 & 14,4 \\
\hline Mistura mineral ${ }^{3}$ & 3,3 & 3,3 & 2,1 & 2,1 \\
\hline \multicolumn{5}{|l|}{ Características da $\operatorname{dieta}^{4}$} \\
\hline Proteína bruta (\% MS) & 11,8 & 13,6 & 14,3 & 15,2 \\
\hline $\begin{array}{l}\text { Energia metabolizável } \\
(\mathrm{MJ} / \mathrm{kg} \mathrm{MS})\end{array}$ & 9,4 & 9,4 & 10,1 & 10,0 \\
\hline
\end{tabular}

1 GPC - ganho diário de peso corporal estimado: alto ( $1 \mathrm{~kg} / \mathrm{animal})$ e baixo $(0,5 \mathrm{~kg} /$ animal $)$.

2 y - Potencial estimado de fermentação microbiana: alto $(11 \mathrm{~g})$ e baixo (9,5 g de proteína bruta metabolizável/MJ de energia metabolizáve fermentável).

${ }^{3}$ Níveis de garantia por kg: Ca - 271 g; P - 29 g; Mg - 20 g; S - 31 g; $\mathrm{Na}-62 \mathrm{~g} ; \mathrm{Zn}-1.350 \mathrm{mg}$; Cu - $340 \mathrm{mg} ; \mathrm{Fe}-1.064 \mathrm{mg} ; \mathrm{Mn}-940 \mathrm{mg}$; Co - $10 \mathrm{mg}$; I - $25 \mathrm{mg}$; e Se - $10 \mathrm{mg}$.

${ }^{4}$ Valores calculados a partir de tabelas de composição de alimentos (NRC, 1996).

(Euclides et al., 1997) e efetuou-se também análise econômica de sensibilidade à variação de $5 \%$ no preço final de comercialização dos animais.

\section{Resultados e Discussão}

Os dados de composição da forragem e do resíduo (Tabela 2) foram agrupados em fase inicial e fase final de pastejo: períodos 1 a 3 ( 1 a 84 dias) e períodos 4 a 6 (85 a 168 dias). Esse modelo de organização dos dados foi adotado em virtude das modificações decorrentes da pluviosidade registrada no final do terceiro período (56 a 84 dias) e início do quarto período de (85 a 112 dias) de pastejo (Figura 1). Essa precipitação nos meses de agosto e setembro favoreceu a rebrota da forrageira e modificou seu teor protéico no momento da entrada dos animais no piquete. Também proporcionou alterações na fração fibrosa da forragem. Gerdes et al. (2000) estudaram a composição do cultivar Marandu no decorrer do ano e obtiveram médias de $13 \%$ de PB e $62,3 \%$ de FDN no período de inverno, efetuando cortes a $15 \mathrm{~cm}$ do solo, após 35 dias de descanso e adubação com nitrogênio (100 kg/ha) no período chuvoso. A composição da forragem utilizada neste trabalho foi semelhante à descrita por Manella et al. (2002), que, em estudo com animais mantidos em pastos de capim-marandu, forneceram concentrado durante a época seca e verificaram que a forrageira, ofertada no nível de 4,52 t de MS/ha, apresentou 5,1\% de PB, 74,8\% de FDN e $42,7 \%$ de FDA na MS. 
Tabela 2 - Composição química média do capim-marandu disponível e do resíduo de pastejo nos períodos de avaliação

\begin{tabular}{|c|c|c|c|c|c|c|c|}
\hline & $\operatorname{MS}^{1}(\%)$ & $\mathrm{PB}$ & $\mathrm{EE}$ & MM & $\mathrm{CT}$ & FDN & FDA \\
\hline & & \multicolumn{6}{|c|}{$\% \mathrm{MS}$} \\
\hline \multicolumn{8}{|l|}{ Forragem disponível } \\
\hline Fase inicial (1 a 84 dias) & 47,52 & 4,93 & 1,35 & 5,63 & 88,09 & 80,02 & 40,52 \\
\hline Fase final ( 85 a 168 dias) & 28,47 & 14,47 & 1,92 & 9,15 & 74,46 & 72,95 & 33,00 \\
\hline \multicolumn{8}{|l|}{ Resíduo } \\
\hline Fase inicial ( 1 a 84 dias $)$ & 69,23 & 4,47 & 0,80 & 7,41 & 87,32 & 81,77 & 45,84 \\
\hline Fase final ( 85 a 168 dias) & 49,81 & 4,66 & 1,15 & 7,30 & 86,89 & 82,11 & 44,00 \\
\hline
\end{tabular}

${ }^{1}$ MS - matéria seca; PB - proteína bruta; EE - extrato etéreo; MM - matéria mineral; CT - carboidratos totais; FDN - fibra em detergente neutro; FDA - fibra em detergente ácido.

O resíduo deixado pelos animais durante o período experimental foi semelhante, indicando que o pastejo pelos animais foi eficiente em colher o material disponível, uma das características do sistema de uso rotativo da pastagem.

A oferta de MS de forragem no decorrer do experimento (Figura 2), estimada pelo método do quadrado (McMenimam, 1997), foi de $14,8 \mathrm{~kg}$ de MS/100 $\mathrm{kg}$ de peso vivo, com médias de 20,7 e 9,2, respectivamente, para a primeira e segunda metade do período experimental, ou seja, foi possível observar duas fases distintas na oferta de forragem durante o ensaio. A primeira metade foi caracterizada pela oferta de forragem de composição qualitativa regular e quantidade apreciável, enquanto, no período final, houve ampliação da qualidade nutricional, mas com oferta reduzida, ou seja, a precipitação não induziu aumento significativo de produção de MS. Até a primeira metade do ensaio, foi oferecido $1 \mathrm{~kg}$ de $\mathrm{PB} / 100 \mathrm{~kg}$ de peso vivo no pasto, valor que passou para 1,33 na segunda metade do ensaio.

A ingestão diária média de forragem observada foi de $5,91 \mathrm{~kg}$ MS/animal, equivalente a 1,78\% do peso corporal. Esse valor foi menor que o observado por Euclides et al. (2000), de 2\%, em estudo com novilhos Nelore mantidos em pasto também de capim-marandu durante a estação seca,

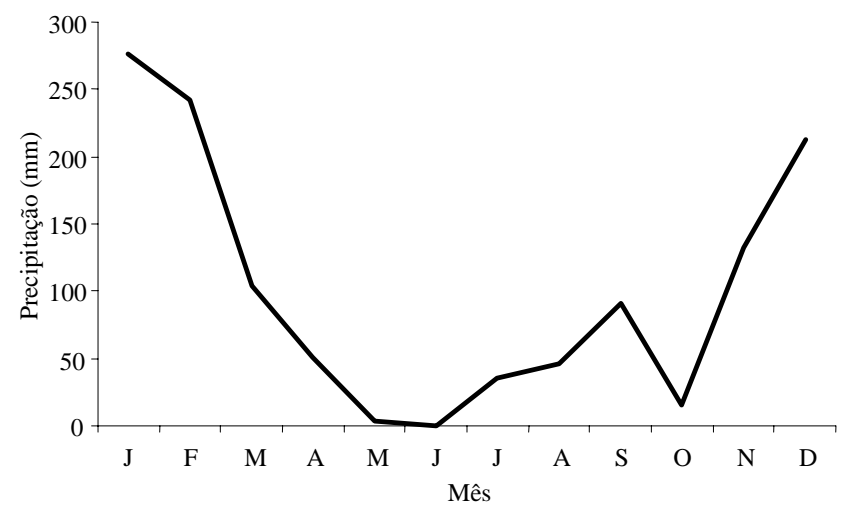

Figura 1 - Precipitação ocorrida durante o período experimental. sem suplementação, mas com disponibilidade de forragem de 2,55 t de MS/ha, superior à estimada neste trabalho no início do período experimental, de 1,5 t/ha. Esses autores reportaram ingestão de $\mathrm{FDN}$ de $1,4 \mathrm{~kg} / 100 \mathrm{~kg}$ do peso corporal e inferiram que o consumo de forragem poderia ter sido limitado pelo enchimento do rúmen a partir da ingestão $1,2 \mathrm{~kg}$. Houve evidências de que a suplementação, naquelas condições, seria necessária para se obterem níveis produtivos elevados, pois o ganho de peso corporal foi de $170 \mathrm{~g} / \mathrm{dia}$.

A ingestão de suplemento (Tabela 3) e de nutrientes diferiu quando considerado o potencial de ganho de peso corporal, mas não diferiu quando considerados os potenciais de fermentação microbiana. A diferença significativa na ingestão de suplemento para os ganhos de peso corporal está relacionada aos níveis de suplementação propostos, ou seja, ao aumento do aporte nutricional diário necessário à manutenção do nível mais elevado de ganho de peso. Conseqüentemente, os animais que receberam suplemento para GPC diário de $1 \mathrm{~kg} /$ animal apresentaram maior ingestão diária de energia metabolizável (EM).

Quando considerada a quantidade de PB e de proteína degradável no rúmen (PDR) ingerida diariamente, verificou-se efeito significativo da interação GPC $\times$ y

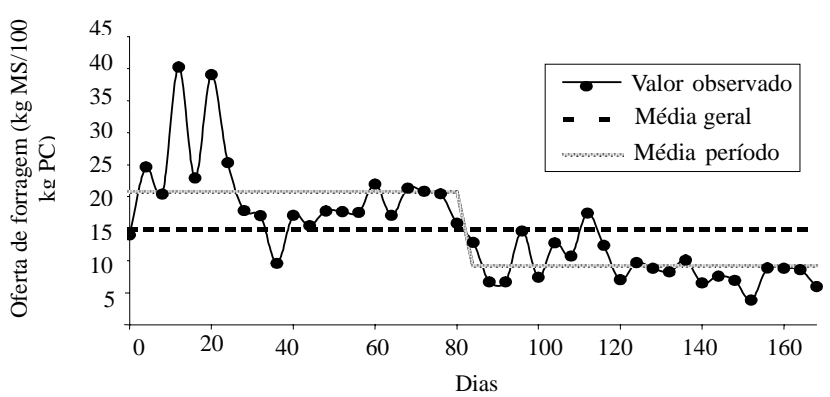

Figura 2 - Oferta de matéria seca (MS) de forragem calculada de acordo com o peso corporal (PC) dos animais, estimada pelo método do quadrado (McMeniman, 1997). 
Tabela 3 - Ingestão diária de nutrientes e suplementos balanceados para diferentes potenciais de fermentação e produção por bezerros Canchim em pastagem de capim-marandu

\begin{tabular}{|c|c|c|c|c|c|c|c|}
\hline \multirow[t]{2}{*}{ Ingestão diária de suplemento } & \multicolumn{2}{|c|}{$\mathrm{GPC}^{1}$} & \multirow[b]{2}{*}{$\mathrm{F}$} & \multicolumn{2}{|c|}{$y^{2}$} & \multirow[b]{2}{*}{$\mathrm{F}$} & \multirow[t]{2}{*}{$\mathrm{CV}(\%)$} \\
\hline & Baixo & Alto & & Baixo & Alto & & \\
\hline \multicolumn{8}{|l|}{ Matéria seca } \\
\hline $\mathrm{kg} / \mathrm{animal}$ & 1,82 & 3,46 & $*$ & 2,64 & 2,64 & NS & 7,21 \\
\hline$\%$ peso corporal & 0,59 & 1,04 & $*$ & 0,80 & 0,82 & NS & 12,94 \\
\hline \multicolumn{8}{|l|}{ Energia metabolizável } \\
\hline MJ/animal & 21,1 & 40,7 & $*$ & 31,2 & 30,7 & NS & 7,23 \\
\hline $\mathrm{MJ} / 100 \mathrm{~kg}$ peso corporal & 6,9 & 12,84 & $*$ & 9,6 & 9,6 & NS & 12,84 \\
\hline \multicolumn{8}{|l|}{$\%$ do peso corporal } \\
\hline Proteína bruta & 0,17 & 0,28 & $*$ & 0,20 & 0,25 & NS & 14,58 \\
\hline Proteína degradável no rúmen & 0,12 & 0,18 & $*$ & 0,13 & 0,17 & NS & 15,59 \\
\hline
\end{tabular}

NS - não-significativo, * - significativo a $5 \%$ de probabilidade pelo teste $\mathrm{F}$.

${ }^{1}$ GPC - Ganho diário estimado de peso corporal: alto (1 kg/animal) e baixo $(0,5 \mathrm{~kg} / \mathrm{animal})$.

2 y - Potencial estimado de fermentação microbiana: alto $(11 \mathrm{~g})$ e baixo $(9,5 \mathrm{~g}$ de proteína bruta metabolizável/MJ de energia metabolizável fermentável).

(Tabela 4). As ingestões de PB e PDR diferiram significativamente entre os potenciais de fermentação para alto e baixo GPC, assim como entre os potenciais de ganho de peso dentro do alto e do baixo potencial de fermentação. Os níveis de suplementação propostos determinaram comportamentos diferentes para a ingestão de cada nutriente avaliado.

Como conseqüência da maior ingestão de nutrientes, o ganho de peso foi mais elevado no nível de suplemento para alto GPC (Tabela 5). A formulação da dieta para baixo GPC utilizando o modelo AFRC (1993) subestimou o ganho de peso corporal, uma vez que os animais apresentaram ganhos de $0,94 \mathrm{~kg} / \mathrm{dia}$, superiores ao preconizado pela composição do suplemento, de $0,5 \mathrm{~kg} / \mathrm{dia}$. Esse fato pode ter sido ocasionado pelas condições do sistema produtivo onde foi desenvolvido o modelo, ou mesmo por terem sido utilizados animais jovens, que tendem a apresentar maiores taxas de desenvolvimento nesta fase da vida, sobretudo quando a raça é especializada para produção de carne.

Melhor conversão alimentar foi observada para o suplemento ajustado para menor GPC. Valor semelhante ao deste trabalho para alto GPC foi observado por Euclides et al. (2001), que verificaram conversão alimentar de 3,18 quando forneceram suplemento na quantidade de $0,8 \%$ do peso corporal a novilhos jovens mestiços mantidos em pastagens de Brachiaria decumbens. Segundo esses autores, os animais que receberam suplemento e aqueles que não receberam apresentaram ganho de peso durante a seca de $490 \mathrm{e}$ 70 g/animal/dia, respectivamente. Neste trabalho, a suplementação para alto GPC foi de 1,04\% do peso corporal, portanto, a eficiência de ganho observada por Euclides et al. (2001) foi maior. Entretanto, a conversão obtida neste trabalho com a suplementação para baixo GPC foi mais eficiente.
Tabela 4 - Ingestão diária de proteína bruta (PB) e proteína degradável no rúmen (PDR) pelos concentrados por bezerros Canchim em pastagem de capim-marandu recebendo suplementos balanceados para diferentes potenciais de fermentação e produção

\begin{tabular}{|c|c|c|c|c|}
\hline \multirow[t]{2}{*}{$\mathrm{GPC}^{1}$} & \multicolumn{2}{|c|}{$y^{2}$} & \multirow[t]{2}{*}{ Média } & \multirow[t]{2}{*}{$\mathrm{CV}(\%)$} \\
\hline & Baixo & Alto & & \\
\hline \multirow{5}{*}{$\begin{array}{l}\text { Baixo } \\
\text { Alto } \\
\text { Média }\end{array}$} & \multicolumn{2}{|c|}{$\begin{array}{c}\text { Ingestão diária PB } \\
(\mathrm{kg} / \text { animal })\end{array}$} & \multirow[b]{2}{*}{0,51} & \multirow{5}{*}{7,05} \\
\hline & $0,44 \mathrm{Bb}$ & $0,58 \mathrm{Ba}$ & & \\
\hline & $0,83 \mathrm{Ab}$ & $1,02 \mathrm{Aa}$ & 0,92 & \\
\hline & 0,64 & 0,80 & - & \\
\hline & \multicolumn{2}{|c|}{$\begin{array}{c}\text { Ingestão diária PDR } \\
(\mathrm{kg} / \text { animal })\end{array}$} & & \\
\hline Baixo & $0,31 \mathrm{Bb}$ & $0,41 \mathrm{Ba}$ & 0,36 & \\
\hline Alto & $0,52 \mathrm{Ab}$ & $0,68 \mathrm{Aa}$ & 0,60 & \\
\hline Média & 0,41 & 0,54 & - & 8,64 \\
\hline
\end{tabular}

Médias seguidas de letras iguais, minúsculas (linha) e maiúsculas (coluna), não diferem entre si pelo teste de Tukey a $5 \%$.

${ }^{1} \mathrm{GPC}$ - ganho diário estimado de peso corporal: alto ( $\left.1 \mathrm{~kg} / \mathrm{animal}\right)$ e baixo $(0,5 \mathrm{~kg} /$ animal).

2 y - potencial estimado de fermentação microbiana: alto $(11 \mathrm{~g})$ e baixo (9,5 g de proteína bruta metabolizável/MJ de energia metabolizável fermentável).

Thiago \& Silva (2000) alertaram para o custo do ganho adicional obtido por unidade de suplemento fornecida acima do necessário para manutenção do peso corporal do animal, especialmente nos casos em que a quantidade diária fornecida ultrapasse $1 \%$ do peso corporal. Os fatores que causam este resultado inadequado são vários e alguns ainda permanecem pouco esclarecidos. Neste trabalho, poderia ter ocorrido efeito associativo negativo nos maiores níveis de suplementação, com a redução do pH ruminal e da digestão da fibra (Brito et al., 2006, 2007b), o que contribuiria para o chamado efeito de substituição, no qual a perfeita complementação da dieta não seria verificada, e o custo do 
Tabela 5 - Desempenho de bezerros Canchim mantidos em pastagem de capim-marandu recebendo suplementos balanceados para diferentes potenciais de fermentação e produção

\begin{tabular}{|c|c|c|c|c|c|c|c|}
\hline \multirow[t]{2}{*}{ Variável } & \multicolumn{2}{|c|}{$\mathrm{GPC}^{1}$} & \multirow[b]{2}{*}{$\mathrm{F}$} & \multicolumn{2}{|c|}{$y^{2}$} & \multirow[b]{2}{*}{$\mathrm{F}$} & \multirow[t]{2}{*}{$\mathrm{CV}(\%)$} \\
\hline & Baixo & Alto & & Baixo & Alto & & \\
\hline \multicolumn{8}{|l|}{ Peso corporal $(\mathrm{kg})$} \\
\hline Inicial & 248 & 248 & NS & 249 & 247 & NS & 13,62 \\
\hline Final & 406 & 431 & NS & 417 & 420 & NS & 10,97 \\
\hline Ganho peso corporal (kg/dia) & 0,94 & 1,09 & $*$ & 1,00 & 1,03 & NS & 19,77 \\
\hline \multicolumn{8}{|c|}{ Área de olho-de-lombo ( $\mathrm{cm}^{2} /$ animal $)$} \\
\hline Inicial & 41,7 & 42,4 & NS & 44,0 & 40,1 & NS & 16,90 \\
\hline Final & 57,3 & 63,6 & NS & 61,1 & 59,8 & NS & 13,86 \\
\hline \multicolumn{8}{|c|}{ Espessura de gordura de cobertura (mm/animal) } \\
\hline Final & 3,3 & 3,7 & NS & 3,2 & 3,8 & $*$ & 9,87 \\
\hline
\end{tabular}

quilograma de carne produzida seria elevado. Ou mesmo os resultados poderiam ser condizentes com a resposta curvilínea do ganho de peso de animais mantidos em pastagem durante a estação seca, em virtude do nível de suplemento oferecido, como demonstrado, entre outros autores, por Lana et al. (2005).

Santos et al. (2002) forneceram suplemento a animais F1 Limousin-Nelore castrados e mantidos em pastagem de Brachiaria decumbens abatidos com 23 meses de idade e relataram peso de carcaça quente de $246,3 \mathrm{~kg}$, AOL de $107,3 \mathrm{~cm}^{2}$ e EGC de 4,8 mm. Esses autores verificaram que o grupo sem suplementação não alcançou o mínimo de 225 $\mathrm{kg}$ de carcaça, mas apresentou o mínimo de $3 \mathrm{~mm}$ de EGC.

O nível de suplemento para alto potencial de fermentação microbiana implicou maior espessura final de gordura de cobertura (Tabela 5). Os potenciais de fermentação microbiana alteraram a concentração de $\mathrm{NH}_{3}$, mas não influenciaram o $\mathrm{pH}$, a produção total e a proporção molar dos ácidos graxos voláteis (Brito et al., 2007b), nem a eficiência de síntese microbiana (Brito et al., 2007a), o que não justificaria a diferença na espessura de gordura de cobertura.

Para o cálculo econômico, considerou-se mesmo rendimento de carcaça para todos os níveis de suplementação, estimado em 52,5\%, em razão do tipo e da idade do animal. O desempenho dos animais que receberam suplementação para baixo GPC foi maior que o previsto, mas, mesmo nesta condição, esses animais não poderiam alcançar o peso de abate mínimo requerido pelos frigoríficos para pagamento integral da categoria, de $225 \mathrm{~kg}$ (Tabela 6).
A produtividade mínima esperada para os níveis de suplemento para alto e baixo GPC foi de 325 e $278 \mathrm{~kg}$ de peso corporal/ha, respectivamente, o que representaria quase cinco vezes a média nacional anual de $65 \mathrm{~kg} / \mathrm{ha}$ em sistemas de criação verticalizados (Zimmer et al., 1998). Média semelhante à observada neste trabalho foi registrada por Manella et al. (2002), que forneceram suplemento a bezerros Nelore mantidos em pastagens de capim-marandu durante a época seca e verificaram produtividade de $299,1 \mathrm{~kg}$ de peso corporal/ha.

Os resultados obtidos neste trabalho representaram bem a diminuição na rentabilidade quando fornecido suplemento para maior GPC. Mesmo assim, a rentabilidade obtida nos níveis de produção foi boa e superior à oferecida por alguns investimentos disponíveis no mercado financeiro. É representativo o valor líquido do fluxo de caixa calculado na suplementação para baixo GPC e baixa fermentação, 532\% maior que o valor obtido com a suplementação para alto GPC e alta fermentação.

Os suplementos com maior potencial de fermentação microbiana reduziram o lucro. O maior aporte de PDR com o suprimento de EMFe promoveu aumento no custo do suplemento, em virtude da natureza onerosa deste nutriente em formulação de dietas. Como os diferenciais de ganho diário de peso corporal não refletiram a magnitude do aumento de custos, houve redução de 7,27 e 25,44\% na rentabilidade mensal da suplementação para maior eficiência de síntese microbiana nos níveis baixo e alto GPC, respectivamente, situação demonstrada também por Silva et al. (2002), ao avaliarem dois níveis de $\mathrm{PB}$ na dieta para a recria e terminação 
Tabela 6 - Perfil bioeconômico da suplementação de bezerros não-castrados Canchim mantidos em pastagem de capim-marandu recebendo suplementos balanceados para diferentes potenciais de fermentação e produção

\begin{tabular}{|c|c|c|c|c|}
\hline \multirow[b]{2}{*}{ Perfil produtivo } & \multicolumn{2}{|c|}{ Baixo GPC ${ }^{1}$} & \multicolumn{2}{|c|}{ Alto GPC } \\
\hline & Baixo $y^{2}$ & Alto y & Baixo y & Alto y \\
\hline Peso inicial do animal (kg) & 249 & 247 & 250 & 246 \\
\hline Ingestão diária concentrado (kg/animal) & 1,81 & 1,84 & 3,48 & 3,44 \\
\hline Ganho de peso diário (kg/animal) & 0,92 & 0,96 & 1,08 & 1,10 \\
\hline Peso de abate $(\mathrm{kg})$ & 403 & 408 & 432 & 431 \\
\hline Rendimento de carcaça quente (\%) & 52,5 & 52,5 & 52,5 & 52,5 \\
\hline Peso da carcaça quente $(\mathrm{kg})$ & 211,6 & 214,2 & 226,8 & 226,3 \\
\hline \multicolumn{5}{|l|}{ Perfil econômico ( $\mathrm{R} \$ /$ animal $)^{3}$} \\
\hline Custo inicial do animal & 515,00 & 515,00 & 515,00 & 515,00 \\
\hline Custo do concentrado & 123,24 & 140,21 & 220,23 & 237,74 \\
\hline Pastagem & 68,32 & 68,32 & 68,32 & 68,32 \\
\hline Outros custos & 21,28 & 23,17 & 32,06 & 34,01 \\
\hline Líquido (R\$/animal) & 132,56 & 124,38 & 86,71 & 65,12 \\
\hline VPL $(\mathrm{R} \$ / \text { animal })^{4}$ & 80,86 & 72,51 & 33,91 & 12,78 \\
\hline TIR (\% am) & 2,75 & 2,55 & 1,69 & 1,26 \\
\hline
\end{tabular}

1 GPC - Ganho diário estimado de peso corporal: alto $(1 \mathrm{~kg} /$ animal) e baixo $(0,5 \mathrm{~kg} /$ animal $)$;

2 y - Potencial estimado de fermentação microbiana: alto $(11 \mathrm{~g})$ e baixo $(9,5 \mathrm{~g}$ de proteína bruta metabolizável/MJ de energia metabolizável fermentável).

3 R\$ 3,00 = US\$1.00; valor da @ boi gordo R\$61,00 FOB fazenda; outros custos = 10\% do total; pasto = 20\% @ /animal $/ \mathrm{mês}$ ).

4 VPL - Valor presente líquido na taxa de desconto de $1 \%$ am; TIR - taxa interna de retorno.

de novilhos Nelore. Os autores constataram que o nível de $18 \%$ de PB aumentou em 10,39\% o custo do quilograma da carcaça produzida em comparação ao nível de $15 \%$.

Euclides et al. (2001) avaliaram o resultado econômico da suplementação de novilhos Angus $\times$ Nelore mantidos em Brachiaria decumbens e abatidos aos $460 \mathrm{~kg}$ e encontraram valor líquido negativo para todos os níveis de suplementação em relação aos animais que não receberam concentrado. Esses autores informaram que mesmo aumentos de $10 \%$ no preço de comercialização viabilizariam apenas um dos níveis de suplementação avaliados.

Nesta pesquisa, avaliou-se a sensibilidade do resultado econômico com a variação de $5 \%$ no preço de comercialização do animal (Tabela 7). Verificou-se que a redução de $5 \%$ no preço de comercialização inviabilizaria a produção no nível de suplementação para alto GPC, pois ambos não suportariam a taxa de desconto de fluxo de caixa mensal de $1 \%$.
Assim, torna-se evidente a importância da avaliação técnica e bioeconômica antes de decisões de adoção de determinada tecnologia ou do investimento em pecuária de corte. De acordo com os resultados obtidos, se o preço da arroba diminuísse de $\mathrm{R} \$ 61,00$ para $\mathrm{R} \$ 58,00$, o produtor teria prejuízos na suplementação para alto GPC. A margem de lucro do produtor com a pecuária de corte tem sido cada vez menor, portanto, é necessária uma avaliação criteriosa das tecnologias a serem adotadas no sistema e o retorno biológico e financeiro dessas incorporações.

Euclides et al. (2001) também alertaram para o fato de que este tipo de resultado revela o risco associado à adoção de inovações em geral e especificamente a suplementação de pastagens na seca. De acordo com esses autores, as interações são específicas e o produtor precisa analisar criteriosamente suas condições, com o máximo de informações, para tomar a decisão mais acertada.

Tabela 7 - Análise de sensibilidade à variação de $5 \%$ no preço de venda do animal sobre o valor econômico da suplementação de bezerros Canchim não-castrados em pastagens de capim-marandu

\begin{tabular}{|c|c|c|c|c|c|}
\hline \multirow[b]{2}{*}{ Variação } & & \multicolumn{2}{|c|}{ Baixo GPC $^{1}$} & \multicolumn{2}{|c|}{ Alto GPC } \\
\hline & & Baixo $y^{2}$ & Alto y & Baixo y & Alto $\mathrm{y}$ \\
\hline \multirow[t]{2}{*}{$-5 \%$} & $\mathrm{VPL}^{4}$ & 44,40 & 35,55 & $-5,44$ & $-26,47$ \\
\hline & TIR (\%am) & 1,99 & 1,78 & 0,89 & 0,45 \\
\hline \multirow{2}{*}{$+5 \%$} & VPL & 117,32 & 109,46 & 73,25 & 52,03 \\
\hline & TIR (\%am) & 3,48 & 3,29 & 2,46 & 2,02 \\
\hline
\end{tabular}

1 GPC - Ganho diário estimado de peso corporal: alto $(1 \mathrm{~kg} / \mathrm{animal})$ e baixo $(0,5 \mathrm{~kg} / \mathrm{animal})$.

2 y - Potencial estimado de fermentação microbiana: alto $(11 \mathrm{~g})$ e baixo $(9,5 \mathrm{~g}$ de proteína bruta metabolizável/MJ de energia metabolizável fermentável).

3 R $3,00=$ US $\$ 1.00$.

4 Valor presente líquido na taxa de desconto de $1 \%$ am; TIR - taxa interna de retorno. 


\section{Conclusões}

A formulação de suplementos para altos ganhos de peso para bezerros não-castrados Canchim em terminação mantidos em pastagem de Brachiaria brizantha cv. Marandu proporciona bom desempenho aos animais, mas o resultado econômico precisa ser considerado pontualmente, uma vez que ocorre aumento do custo da carcaça produzida. Quando o concentrado é formulado para promover ganhos intermediários, o desempenho dos animais é superior ao esperado e os resultados econômicos são melhores. A suplementação durante seis meses após a desmama, no entanto, não é suficiente para que os animais atinjam o peso mínimo de carcaça para remuneração nesta categoria. A formulação de suplemento para esses bezerros durante a estação seca do ano com o intuito de aumentar a eficiência de síntese de proteína microbiana no rúmen não influencia o desempenho animal e reduz a rentabilidade do sistema produtivo.

\section{Literatura Citada}

AGRICULTURAL AND FOOD RESEARCH COUNCIL - AFRC. Energy and protein requirements of ruminants. Wallingford: Cab International, 1993. 159p.

BONFIM, M.A.D.; REZENDE, C.A.P.; PAIVA, P.C.A. et al. Níveis de concentrado na terminação de novilhos holandês $\mathrm{x}$ zebu suplementados a pasto na estação seca. Ciência e Agrotecnologia, v. 25 , n.6, p. 1457-1466, 2001

BRITO, R.M.; SAMPAIO, A.A.M.; FERNANDES, A.R.M. et al. Digestibilidades parcial e total de dietas com feno de capimmarandu e concentrado, balanceadas para diferentes níveis de produção. Revista Brasileira de Zootecnia, v.35, n.4, p.1796-1804, 2006 (supl.).

BRITO, R.M.; SAMPAIO, A.A.M.; FERNANDES, A.R.M. et al. Aporte de energia, composição e eficiência microbiana em bovinos alimentados com feno de capim-marandu e concentrado balanceados para diferentes ganho de peso e potenciais de fermentação microbiana. Revista Brasileira de Zootecnia, v.36, n.5, p.1630-1638, 2007a (supl.).

BRITO, R.M.; SAMPAIO, A.A.M.; FERNANDES, A.R.M. et al. Degradabilidade in situ e parâmetros ruminais em bovinos alimentados com dietas balanceadas para diferentes ganho de peso e potenciais de fermentação microbiana. Revista Brasileira de Zootecnia, v.36, n.5, p.1639-1650, 2007b (supl.).

BURGÜER, P.J.; PEREIRA, J.C.; QUEIROZ, A.C. et al. Comportamento ingestivo em bezerros holandeses alimentados com dietas contendo diferentes níveis de concentrado. Revista Brasileira de Zootecnia, v.29, n.1, p.236-242, 2000.

EUCLIDES, V.P.B.; EUCLIDES FILHO, K.; ARRUDA, Z.J. Alternativas de suplementação para redução da idade de abate de bovinos em pastagem de Brachiaria decumbens. Campo Grande: EMBRAPA-CNPGC, 1997. 25p. (Circular Técnica, 25).

EUCLIDES, V.P.B.; CARDOSO, E.G.; MACEDO, M.C.M. et al. Consumo voluntáro de Brachiaria decumbens cv. Basilisk e Brachiaria brizantha cv. Marandu sob pastejo. Revista Brasileira de Zootecnia, v.29, n.2, p.545-554, 2000

EUCLIDES, V.P.B.; EUCLIDES FILHO, K.; COSTA, F.P. et al Desempenho e novilhos F1 Angus-Nelore em pastagem de
Brachiaria decumbens submetidos a diferentes regimes alimentares. Revista Brasileira de Zootecnia, v.30, n.2, p.479-481, 2001.

GERDES, L.; WERNER, J.C.; CALAZZA, M.T. et al. Avaliação de características de valor nutritivo das gramíneas forrageiras Marandu, Setária e Tanzânia nas estações do ano. Revista Brasileira de Zootecnia, v.29, n.4, p.955-963, 2000.

LANNA, D.P.D. Fatores condicionanates e predisponentes da puberdade e da idade de abate. In: SIMPÓSIO SOBRE PECUÁRIA DE CORTE, 4., 1996, Piracicaba. Anais... Piracicaba: Fundação de Estudos Agrários Luiz de Queiroz, 1996. p.41-78.

MANELLA, M.Q.; LOURENÇO, A.J.; LEME, P.R. Recria de bovinos Nelore em pastos de Brachiaria brizantha com suplementação protéica ou com acesso a banco de proteína de Leucaena leucocephala. Desempenho animal. Revista Brasileira de Zootecnia, v.31, n.6, p.2274-2282, 2002.

McMENIMAN, N.P. Methods of estimating intake of grazing animals. In: SIMPÓSIO SOBRE TÓPICOS EM ZOOTECNIA, 34., 1997, Juiz de Fora. Anais... Juiz de Fora: Sociedade Brasileira de Zootecnia, 1997. p.131-168.

NATIONAL RESEARCH COUNCIL - NRC. Nutrient requirements of beef cattle. 6.ed. Washington. D.C.: National Academy Press, 1996. 242p.

PAULINO, M.F.; DETMMAN, E.; VALADARES FILHO, S.C. et al. Soja grão e caroço de algodão em suplementos múltiplos para terminação de bovinos mestiços em pastejo. Revista Brasileira de Zootecnia, v.31, n.1, p.484-491, 2002. (supl.).

PENATI, M.A.; CORSI, M.; LIMA, C.G. et al. Número de amostras e relação dimensão:formato da moldura de amostragem para determinação da massa de forragem de gramíneas cespitosas. Revista Brasileira de Zootecnia, v.34, n.1, p.36-43, 2005

PERRY, T.D.; FOX, D.G. Predicting carcass composition and individual feed requirement in live cattle widely varying in body size. Journal of Animal Science, v.70, n.4, p.10021010,1992

PRATES, E.R.; BONELLI, I.B.; PIAGGIO, L.M. et al. Tempo e ciclo diários de pastejo de novilhos mantidos em condições de pastagem nativa melhorada. Revista Brasileira de Zootecnia, v.24, n.1, p.1-7, 1995.

RESTLE, J.; NEUMANN, M.; BRONDANI, I.L. et al. Produção do superprecoce a partir de bezerros desmamados aos 72 ou 210 dias de idade. Revista Brasileira de Zootecnia, v.31, n.4, p.1803-1803, 2002.

ROBINSON, D.L.; MCDONALD, C.A.; HAMMOND, K. et al. Live animal measurement of carcass traits by ultrasound: assessment and accuracy of sonographers. Journal of Animal Science, v.31, n.4. p.1803-1813, 1992.

ROCHA, M.G.; LOBATO, J.F.P. Sistemas de alimentação pósdesmama de bezerros de corte para acasalamento com 14/15 meses de idade. Revista Brasileira de Zootecnia, v.31, n.4, p.1814-1822, 2002.

SAMPAIO, A.A.M.; BRITO, R.M.; VIEIRA, P.F. et al. Efeito da suplementação protéica sobre o crescimento, terminação e viabilidade econômica de bezerros mestiços Canchim confinados pós-desmama. Revista Brasileira de Zootecnia, v.31, n.4, p. 823-831, 1998 .

SAMPAIO, I.B.M. Estatística aplicada à experimentação animal. Belo Horizonte: Fundação de Ensino e Pesquisa em Medicina Veterinária e Zootecnia, 1998. 221p.

SANTOS, E.D.G.; PAULINO, M.F.; LANA, R.P. et al. Influência da suplementação com concentrados nas características de carcaça de bovinos F1 Limousin-Nelore, não castrados, durante a seca, em pastagens de Brachiaria decumbens. Revista Brasileira de Zootecnia, v.31, n.4, p.1823-1832, 2002.

SILVA, D.J. Análise de alimentos: métodos químicos e biológicos. 2.ed. Viçosa, MG: Universidade Federal de Viçosa, 1990. 165p.

SILVA, F.F.; VALADARES FILHO, S.C.; ITAVO, L.C.V. et al. Desempenho produtivo de novilhos Nelore, na recria e engorda, recebendo dietas com diferentes níveis de concentrado e 
proteína. Revista Brasileira de Zootecnia, v.31, n.1, p.492502, 2002 (supl.).

SNIFFEN, C.J.; O'CONNOR, J.D.; Van SOEST, P.J. et al. A net carbohydrate and protein system for evaluating cattle diets: II. Carbohydrate and protein availability. Journal of Animal Science, v.70, n.11, p.3562-3577, 1992.

THIAGO, L.R.L.; SILVA, J.M. Suplementação de bovinos em pastejo. Campo Grande: Embrapa Gado de Corte, 2000. 19p. (Circular Técnica, 27).

Van SOEST, P.J.; ROBERTSON J.B.; LEWIS, B.A. Methods of dietary fiber, neutral detergent fiber, and nostarch polysaccharides in relation to animal nutrition. Journal of Dairy Science, v.74, n.10, p.3583-3597, 1991.

WILLIAMS, R.E.; BERTRAND, J.K.; WILLIAMS, S.E. et al. Biceps femoris and rump fat as additional ultrasound measurements for predicting retail and trimmable fat in beef carcasses. Journal of Animal Science, v.75, n.1, p.7-13, 1997.

ZIMMER, A.H.; EUCLIDES, V.P.B.; EUCLIDES FILHO, K. Considerações sobre índices de produtividade da pecuária de corte em Mato Grosso do Sul. Campo Grande: EMBRAPA/ CNPGC, 1998. 53p. (Documentos, 70). 